\title{
Usefulness of Preoperative FNAC of Thyroid Swelling Along with Application of Bethesda System of Reporting
}

\author{
Neena Kasliwal' ${ }^{1}$, Sonia Tanwar ${ }^{2}$, Geeta Pachori ${ }^{3}$, Neha Gupta ${ }^{4}$, Niti Maheshwari ${ }^{5}$, Deepali Jain ${ }^{5}$ \\ ${ }^{1}$ Professor, ${ }^{2}$ Resident doctor, ${ }^{3}$ Professor \& Head, ${ }^{4}$ Senior Demonstrator, ${ }^{5}$ Assistant Professor, \\ Department of Pathology, JLN Medical College, Ajmer, Rajasthan, INDIA.
}

\begin{abstract}
Introduction: Fine needle aspiration cytology (FNAC) is the commonly used test for diagnosis of thyroid swellings. FNAC is a cost-effective procedure that provides specific diagnosis rapidly with minimal complications. Based on the cytology findings, patients can be subjected to surgery, thereby decreasing the rate of surgery and its consequent complications.
\end{abstract}

Aims and Objective: Study is aimed to accuracy of FNAC in thyroid as compare with histopathology and classify various cytomorphological lesions of thyroid according to The Bethesda System for Reporting of Thyroid Cytopathology (TBSRTC).

Material and Methods: This prospective study was done at our department from January 2013 to June 2015. Total 411 cases presented with thyroid swelling were subjected to thyroid fine needle aspiration cytology (FNAC) and the smears were made followed by routine staining and reporting. The categorization according to the Bethesda system of reporting thyroid cytology was done. The cytological diagnosis was correlated with the histological diagnosis wherever it was available. The accuracy of FNAC for the diagnosis of nonneoplastic and neoplastic lesions was determined using histopathology as the gold standard.

Results: Out of total 411 cases, 387 (94.16\%) were benign, 15 $(3.52 \%)$ were Follicular neoplasm, $7(1.70 \%)$ cases were malignant and $2(0.48 \%)$ were inadequate. Most frequently encountered lesion was colloid goitre in $217(52.79 \%)$ cases

\section{INTRODUCTION}

Thyroid diseases are frequently encountered endocrine disorders in clinical practice. Majority of these are benign, of which Goitre is the commonest. Only a few are malignant. The prevalence of goitre is more than 40 million in India with more than 2 billion globally. ${ }^{1}$

The prevalence of thyroid swelling ranges from $4 \%$ to $10 \%$ in the general adult population and from $0.2 \%$ to $1.2 \%$ in children. The majority of clinically diagnosed thyroid swelling is non-neoplastic; only $5 \%-30 \%$ are malignant and require surgical intervention. ${ }^{2}$

Percentage of solitary thyroid nodule increases linearly with age along with increased prevalence of malignancy in third, fourth and fifth decades of life. Thyroid tumors are more prevalent in females and papillary carcinoma is the most common histological type of thyroid tumors followed by follicular carcinoma, medullary carcinoma, anaplastic carcinoma, non-Hodgkin's lymphoma and unclassified tumors in order of frequency. ${ }^{3}$

Fine needle aspiration technique was evolved first time by Martin and Ellis in 1934. ${ }^{4}$ Subsequently Franzen et al (1968) described followed by thyroiditis in $75(18.24 \%)$ cases, 67 (16.30\%) cases of nodular goitre, $26(6.32 \%)$ cases of hyperplastic goitre and $2(0.48 \%)$ cases of thyroglossal cysts. The cytological and histological concordance was determined in 97 cases. FNA revealed a sensitivity of $85.71 \%$, a specificity of $100 \%$, a positive predictive value of $100 \%$ and a negative predictive value of $98.76 \%$

Conclusion: TBSRTC can help with a better patient's outcome due to proper clinical management of thyroid swellings and saves patients from unnecessary thyroid surgery.

Key Words: FNAC, Thyroid lesions, The Bethesda system.

\section{*Correspondence to:}

Dr. Sonia Tanwar, A-357 Chandervardayi Nagar, Ajmer, Rajasthan, INDIA.

Email: sonia.tanwar2012@gmail.com

Article History:
Received: 06-04-2016, Revised: $12-04-2016$, Accepted: 18-04-2016
\begin{tabular}{|l|c|}
\hline \multicolumn{2}{|c|}{ Access this article online } \\
\hline $\begin{array}{l}\text { Website: } \\
\text { www.jmm.pom }\end{array}$ \\
\hline $\begin{array}{l}\text { DOI: } \\
\text { 10.21276/ijmrp.2016.2.3.045 }\end{array}$
\end{tabular}

the technique of aspiration cytology in detail. ${ }^{5}$ FNAC is being reliable, minimally invasive and is considered the gold standard in evaluation of thyroid swelling. It is a simple, cost effective and having high sensitivity and specificity has been applied routinely as a useful and indispensable method to diagnose thyroid lesions. It can be readily repeated and quick to perform procedure in the outpatient department, with excellent patient compliance. ${ }^{6}$ But like any other test FNAC also has its limitations. The reported pitfalls are those related to specimen adequacy, sampling techniques, the skill of the physician performing the aspiration, the experience of the pathologist interpreting the aspirate and overlapping cytological features between benign and malignant follicular neoplasm. ${ }^{7-9}$

This study aims correlating the cytological diagnosis with the final histopathological diagnosis to evaluate the sensitivity, specificity and predictive values of positive smears, thereby to assess its role in preoperative diagnosis and planning of proper management of Thyroid swellings. 


\section{MATERIALS \& METHODS}

This prospective study was conducted at Department of Pathology J. L. N. Medical College and Hospitals, Ajmer (Rajasthan) over the period of Jan 2013 to June 2015. Appropriate permission had been taken from Institutional ethics committee. Patients who gave informed consent and referred to Pathology laboratory with a clinical diagnosis of Thyroid swelling were included in this study. Uncooperative patients were excluded. All the referred patients, who had undergone routine investigations, were clinically evaluated in detail and a cautious palpation of the thyroid swelling was done to judge in particular the location for aspiration. FNAC was done on the thyroid swelling using a 24-26 gauge needle attached to a $5 \mathrm{ml}$ syringe under aseptic precautions. ${ }^{10}$ Then several smears were prepared and promptly fixed in a fixative containing $95 \%$ ethyl alcohol. These were stained by Hematoxylin and Eosin (H\&E) stain. ${ }^{11}$ Air dried smears were also prepared and stained with May Grunwald's Giemsa stain. Whenever fluid was found, all the contents were made to empty by gentle pressure in the thyroid gland. The fluid was centrifuged for Microscopic examination and smears were made from the sediment and. If residual mass felt, Re-aspiration was done.

At every time the biopsy specimen came in the pathology department, paraffin sections were made and stained by H\&E. Histo-pathological examination was done. A Cytohistopathological correlation of results was done to estimate the efficacy of FNAC. Pre-operative FNAC results were compared with final histopathological diagnosis. Taking histopathology as gold standard criteria, sensitivity, specificity and accuracy were calculated.

\section{RESULTS}

FNAC was performed on thyroid swelling of 411 patients, which included $372(90.51 \%)$ females and $39(9.49 \%)$ males and with F: $\mathrm{M}$ ratio of $9.54: 1$. The average age of total cases was 39.30 years with a range of 6 years to 70 years. The most common presenting symptom was diffuse and or nodular swelling of the thyroid gland. Other symptoms reported by patients were pain in the midline neck, difficulty in swallowing and hoarseness of voice.The maximum number of cases 159 (38.68\%) were presented within the duration of 1-6 months.

The FNAC results revealed $387(94.16 \%)$ cases as nonneoplastic and 15 (3.64\%) cases of Follicular neoplasm and 7 $(1.70 \%)$ cases as neoplastic. On cytological examination a diagnosis of thyroglossal cyst was made in 2 cases $(0.48 \%)$, Colloid goitre was present in $217(52.79 \%)$ cases, Nodular goitre in $67(16.30 \%)$ cases, hyperplastic goitre in $26(6.32 \%)$ cases, Hashimoto's thyroiditis in $46(11.22 \%)$ cases, Lymphocytic thyroiditis in $24(5.38 \%)$ cases, 2 cases of Grave's Disease, 3 cases of Granulomatous thyroiditis. Follicular Neoplasm in 15 $(3.64 \%)$ cases, 3 cases of Medullary Carcinoma, 3 cases of papillary carcinoma and 1 case of metastatic deposits of Breast carcinoma. [Table 1]

According to Bethesda system of classification out of total 411 cases, maximum numbers of cases were in benign category 387 $(94.40 \%)$ cases, $15(3.64 \%)$ cases under the Suspicious for Follicular Neoplasm/Follicular Neoplasm, 7 (1.70\%) cases under malignant category, 2 cases under unsatisfactory smears. There were no cases found under the Atypia with Undetermined Significance and Suspicious for malignancy. [Table 2]

Cytological diagnosis and histological diagnosis of thyroid gland lesions were correlated in 97 cases. Results are found to be consistent in 85 cases (87.62\%) and inconsistent in 12 cases $(12.37 \%$ ). There was 1 false negative case (which was cytologically diagnosed as benign and on histopathology found to be malignant). [Table 3]

The sensitivity, specificity and diagnostic accuracy of FNAC for detection of malignant lesions was $85.71 \%, 100 \%$ and $88.65 \%$ respectively. [Table 4]

Table 1: Routine cytological diagnosis of 411 cases

\begin{tabular}{lccccc}
\hline Cytological diagnosis & Male & Female & Total & Percentage (\%) & pValue \\
\hline Inadequate smear & - & 2 & 2 & 0.48 & \\
Benign & 33 & 354 & 387 & 94.16 & \\
Thyroglossal cyst & 1 & 1 & 2 & 0.48 & \\
Colloid Goitre & 27 & 190 & 217 & 52.79 & \\
Nodular Goitre & 2 & 65 & 67 & 16.30 & \\
Hyperplastic Goitre & 2 & 24 & 26 & 6.32 & $\mathbf{0 . 0 0 2}$ \\
Grave's Disease & - & 2 & 2 & 0.48 & (S) \\
Granulomatous Thyroiditis & - & 3 & 3 & 0.72 & \\
Hashimoto' Thyroiditis & - & 46 & 46 & 11.19 & \\
Lymphocytic Thyroiditis & 1 & 23 & 24 & 5.84 & \\
Malignant & 7 & 15 & 22 & 5.35 & \\
Follicular neoplasm & 5 & 10 & 15 & 3.64 & \\
Papillary carcinoma & 1 & 2 & 3 & 0.72 & \\
Medullary carcinoma & 1 & 2 & 3 & 0.72 & \\
Metastatic breast Carcinoma & - & 1 & 1 & 0.24 & \\
Total & $\mathbf{3 9}$ & $\mathbf{3 7 2}$ & $\mathbf{4 1 1}$ & $\mathbf{1 0 0}$ & \\
\hline Chi-Square=9.30; pValue=0.0022 (significant) & & &
\end{tabular}

Table 2: Diagnostic categorization of 411 thyroid FNACs based on Bethesda classification

\begin{tabular}{lcc}
\hline Categories & Total no. of cases & Percentage (\%) \\
\hline Group 1: Inadequate smear & 2 & 0.48 \\
Group 2: Benign & 387 & 94.16 \\
Group 3: Atypia with Undetermined Significance & 0 & 0 \\
Group 4: Suspicious for FN/FN & 15 & 3.64 \\
Group 5: Suspicious for malignancy & 0 & 0 \\
Group 6: Malignant & 7 & 1.70 \\
Total & 411 & 100 \\
\hline
\end{tabular}


Table 3: Comparison of routine Cytological diagnosis with 97 Histo-pathological Diagnosis

\begin{tabular}{|c|c|c|c|c|c|c|}
\hline $\begin{array}{l}\text { Sr. } \\
\text { No }\end{array}$ & $\begin{array}{l}\text { Histopathological } \\
\text { Diagnosis }\end{array}$ & $\begin{array}{c}\text { Concordance with } \\
\text { Cytological } \\
\text { diagnosis }\end{array}$ & Dis-concordance & $\begin{array}{c}\text { False } \\
\text { Negative }\end{array}$ & $\begin{array}{c}\text { False } \\
\text { Positive }\end{array}$ & $\begin{array}{c}\text { Accuracy } \\
(\%)\end{array}$ \\
\hline 1. & Thyroglossal cyst (1) & 1 & 0 & - & - & 100 \\
\hline 2. & Goitre (72) & 69 & $\begin{array}{l}\text { 3-Thyroglossal Cyst (1) } \\
\text { Hashimoto's thyroiditis } \\
\text { (2) }\end{array}$ & & & 95.83 \\
\hline 3. & Thyroiditis (5) & 3 & 2- Colloid Goitre & & & 60 \\
\hline 4. & Hurthle cell Adenoma (1) & 1 & 0 & & & 100 \\
\hline 5. & Follicular Adenoma(12) & 6 & $\begin{array}{l}\text { 6- Colloid Goitre (4) } \\
\text { Nodular Goitre (2) }\end{array}$ & & & 50 \\
\hline 6. & Follicular Carcinoma (3) & 2 & $\begin{array}{l}\text { 1-Hyperplastic nodular } \\
\text { Goitre }\end{array}$ & 1 & & 66.67 \\
\hline 7. & $\begin{array}{l}\text { Papillary Carcinoma (3) } \\
\text { Total (97) } \\
\text { Percentage }\end{array}$ & $\begin{array}{c}3 \\
85 \\
87.62 \%\end{array}$ & $\begin{array}{c}0 \\
12 \\
12.37 \%\end{array}$ & 1 & & 100 \\
\hline
\end{tabular}

Table 4: Statistical values for thyroid malignant lesions

\begin{tabular}{|c|c|}
\hline True Positive & 6 \\
\hline True Negative & 80 \\
\hline False Positive & 0 \\
\hline False Negative & 1 \\
\hline Sensitivity & 85.71 \\
\hline Specificity & $100 \%$ \\
\hline PPV & $100 \%$ \\
\hline NPV & $98.76 \%$ \\
\hline False positive error rate & 0 \\
\hline False negative error rate & $1.03 \%$ \\
\hline Diagnostic Accuracy & $88.65 \%$ \\
\hline \multicolumn{2}{|c|}{ Sensitivity $=(T P / T P+F N) \times 100 ;$ Specificity $=(T N / T N+F P) \times 100$} \\
\hline \multirow{3}{*}{\multicolumn{2}{|c|}{$\begin{array}{l}\text { Positive predictive value }=(T P / T P+F P) \times 100 ; \text { Negative predictive value }=(T N / T N+F N) \times 100 \\
\text { Diagnostic Accuracy }=(T P+T N / F P+F N+T P+T N) \times 100 \\
\text { False positive error rate }=(\text { FP/Total no. of cases }) \times 100\end{array}$}} \\
\hline & \\
\hline & \\
\hline \multicolumn{2}{|c|}{ False negative error rate $=(\mathrm{FN} /$ Total no. of cases $) \times 10$} \\
\hline
\end{tabular}

\section{DISCUSSION}

FNAC is usually the first line of investigation and other investigations like ultrasound (US) examination, thyroid function tests, thyroid scan, and antibody levels are done subsequently with an aim to select the patients who require surgery and those that can be managed conservatively.

The present study was carried out with an aim to evaluate the role of aspiration cytology in diagnosis of various benign and malignant lesions of thyroid.

Aspiration biopsy is an extension of morphological diagnosis within both cytology and histopathology. It is also a useful tool for the oncologist, who deals with undiagnosed palpable and nonpalpable masses and lesion. It is a short cut to direct diagnosis and can be carried out at the clinic or bed side. It will obviate the need for radiologist and surgical procedure, save time and expenses, and allay anxiety.

In the present study, cytological features of thyroid lesions were studied and correlated with histopathological diagnosis wherever available to determine its diagnostic accuracy.

The age group which was studied ranged from 6 years to 80 years and the mean age of patients with thyroid in our study was 39.3 years. In present study a female preponderance was noted with Male to Female ratio of 1: 9.54. Similar observations were noted by Sekhsar A et al. ${ }^{12}$

Neoplastic lesions were $7(1.70 \%)$ cases, $15(3.64 \%)$ cases of Follicular neoplasm and non-neoplastic lesions were 387 $(94.16 \%)$ cases. Among the non-neoplastic lesion Colloid Goitre $217(52.79 \%)$ cases, Nodular goiter in $67(16.30 \%)$ cases, hyperplastic goiter in $26(6.32 \%)$ cases, Hashimoto's thyroiditis in $46(11.22 \%)$ cases, Lymphocytic thyroiditis in $24(5.38 \%)$ cases, 2 cases of Grave's Disease, 3 cases of Granulomatous thyroiditis and $2(0.48 \%)$ cases were unsatisfactory, similar observations were also made by Handa $U$ et al. ${ }^{13}$

For the purpose of study, the result of various lesion are classified according to the Bethesda System reporting terminology which includes six categories: ${ }^{14}$

In this study Category I or non-diagnostic had 2 cases or $0.48 \%$ in which sufficient material was not available, only cyst fluid, obscuring blood, only macrophage or preparation artifact.

Category II or Benign: majority of cases in our study were benign included in this category, maximum number of cases were colloid goitre $217(52.79 \%)$, followed by thyroiditis $75(18.24 \%)$, nodular goitre $67(16.3 \%)$ and hyperplastic goitre $26(6.32 \%)$, similar observations were made by Dr Vasudha $\mathrm{M}$ et al..$^{15}$

Category III or AUS: It is reserved for specimens that contain cells with architectural and/or nuclear atypia that is not sufficient to be classified as suspicious for a follicular neoplasm. In our study we did not find any case in this category.

Category IV or FN/SFN: The goal of this category is to identify all potential follicular carcinomas and refer them for a diagnostic lobectomy. These cytomorphologic features do not permit distinction from follicular adenoma (FA), they are reportable as Follicular Neoplasm (FN) or suspicious of Follicular Neoplasm (SFN). The majority of FN/SFN cases turn out to be FAs or adenomatoid nodules of multi nodular goitre. Total 15 (3.64\%) cases were found under this category. 


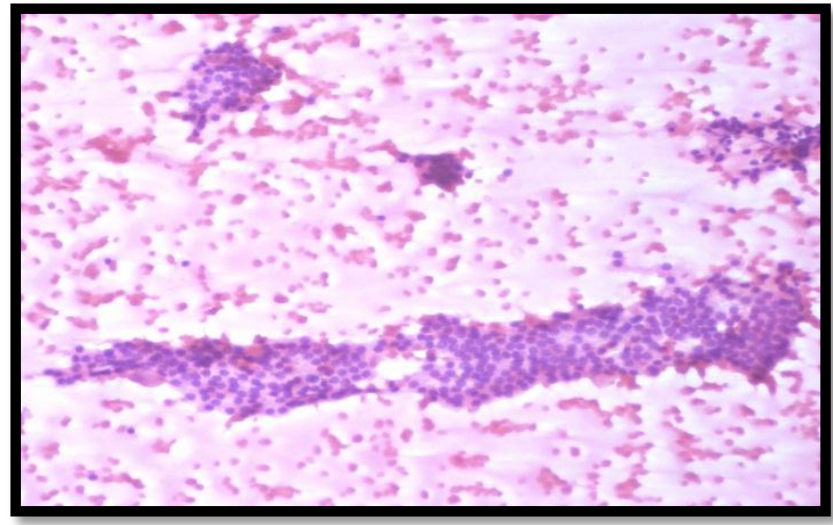

Fig 1: NODULAR GOITER: cytosmear shows monolayered sheet of thyroid follicular cells and clusters of follicular cells against the blood mixed thin colloid. (H \& E; 400X)

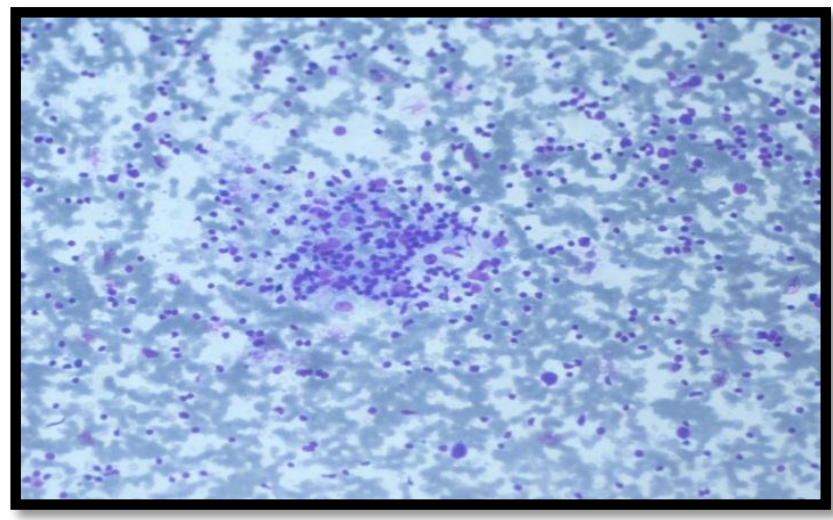

Fig 3: HASHIMOTO'S THYROIDITIS: cytosmear shows few thyroid follicular cells with askanazy change against the background of abundant lymphoid cells mixed with blood. (Giemsa; 100x)

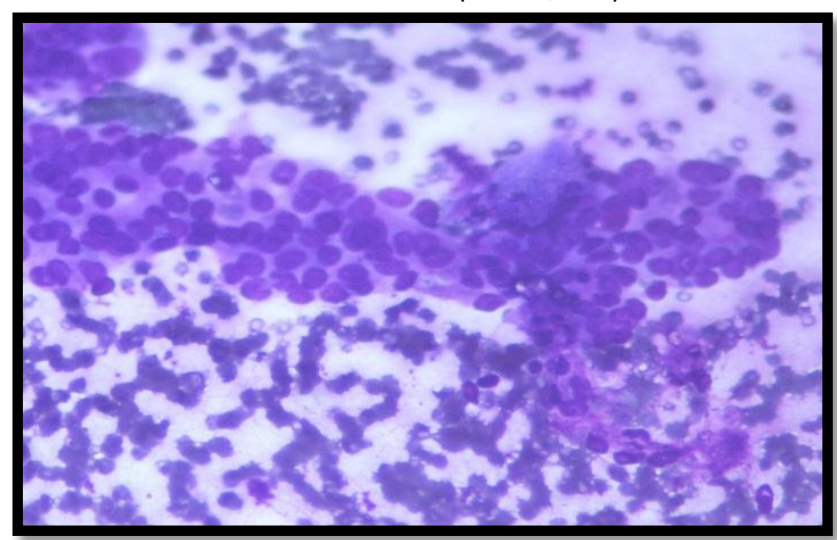

Fig 5: FOLLICULAR NEOPLASM: Cytosmear showing compact microfollicular clusters of follicular epithelial cells with scanty colloid. (Giemsa; 200X)

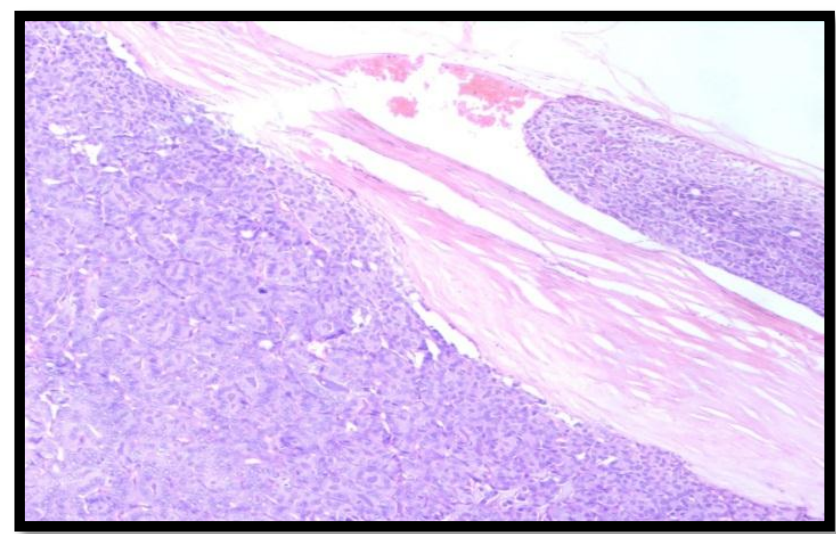

Fig 7: FOLLICULAR CARCINOMA: Tissue sections showing tumor mass and capsular and vascular invasion. (H \& E; 200X)

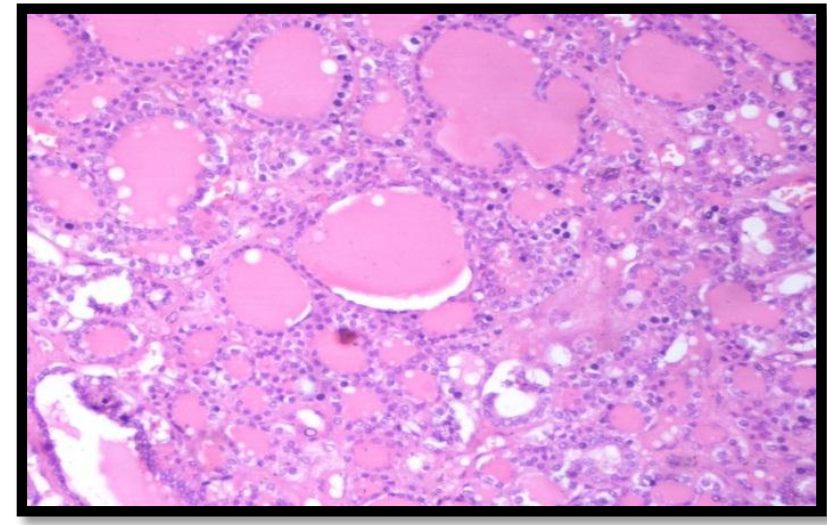

Fig 2: NODULAR GOITER: stained tissue sections shows thyroid filled follicles with flattening of lining epithelium. (H \&E; 100x)

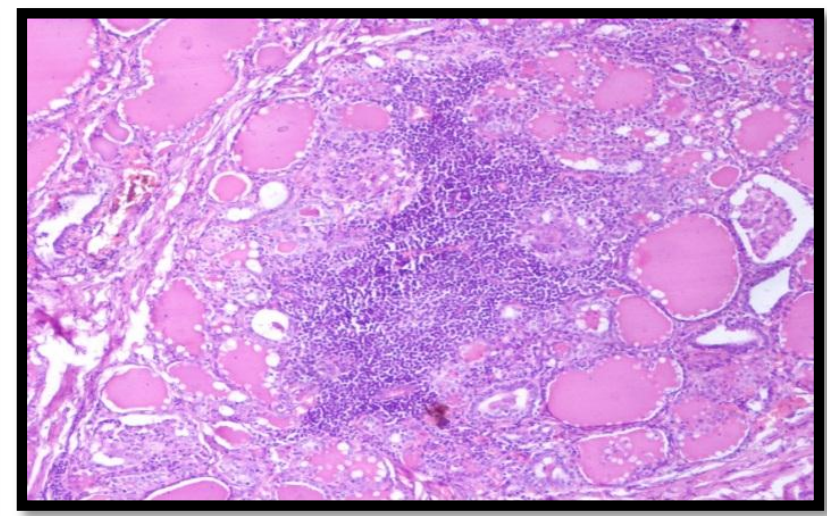

Fig 4: Hashimoto's Thyroiditis: Tissue section showing variable sized colloid filled follicles with dense lymphocytic infiltration and a prominent lymphoid follicle towards right side.(H \& E; 100x)

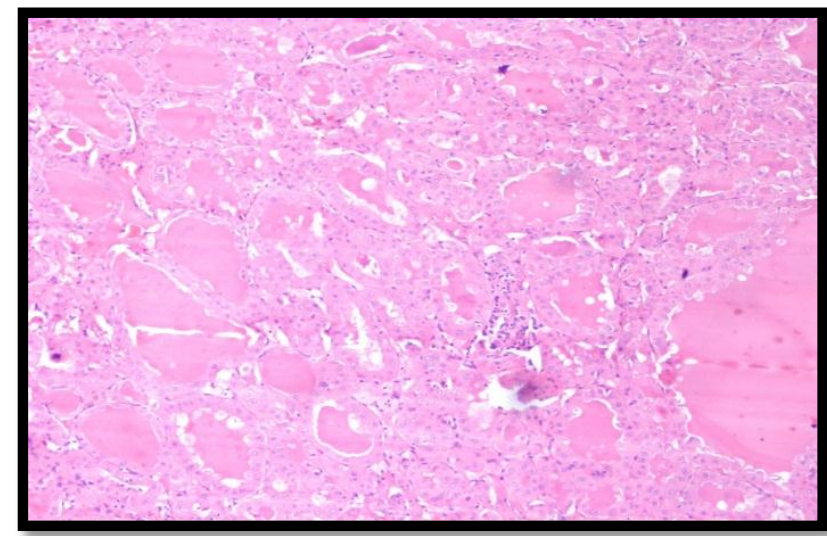

Fig 6: HURTHLE CELL ADENOMA: Tissue section shows follicles lined by cells having abundant eosinophilic granular cytoplasm and vesicular nuclei and colloid. (H \& E; 200x)

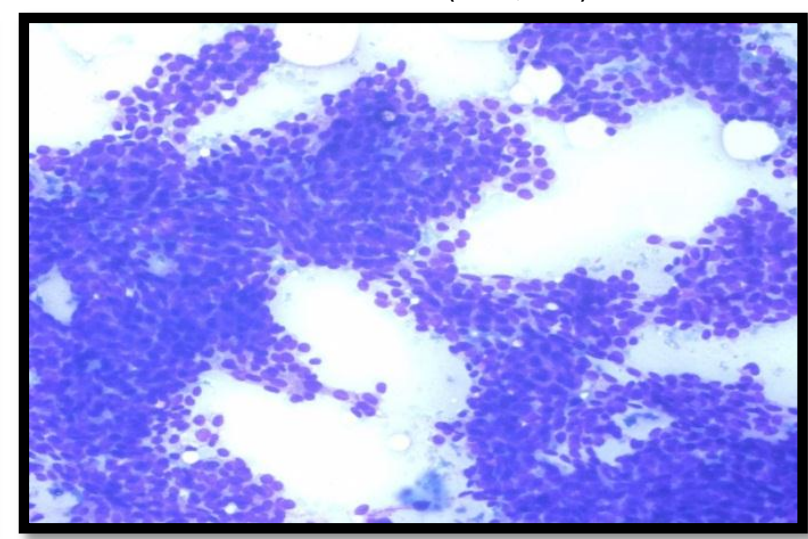

Fig 8: PAPILLARY CARCINOMA: Cells arranged in sheets and in clusters forming papillae with fibrovascular core. (Giemsa; 200X) 


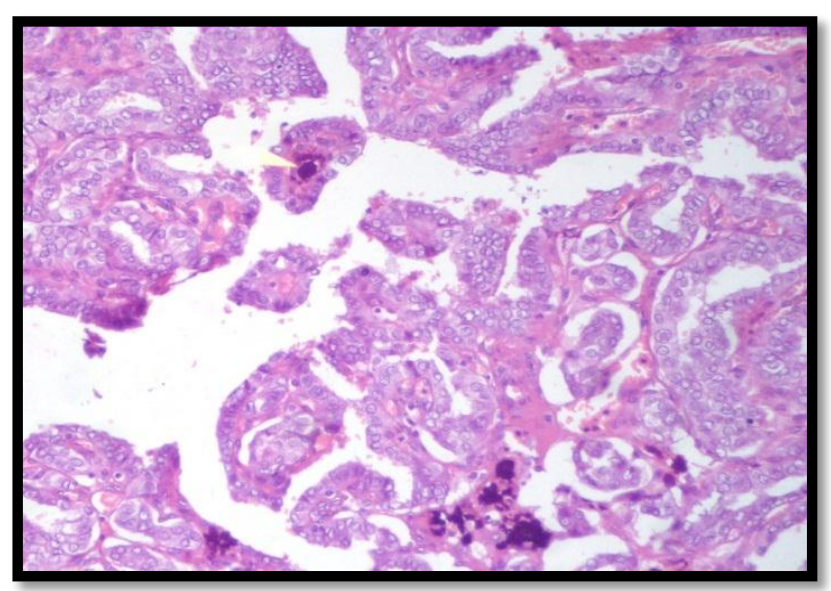

Fig 9: Papillary Carcinoma: Tissue section showing papillae with fibrovascular core and overlapping of nuclei and optically clear nucleus, nuclear grooving and at places showing calcifications. (H \& E; 200X)

Category $\mathrm{V}$ or suspicious for malignancy: If there is 1 or 2 characteristic of malignancy present and they are only focal and not widespread throughout the follicular cell population, or if sample is sparsely cellular, a diagnosis cannot be made with certainty. In our study we did not find any case in this category.

Category VI or Malignant: The malignant category is used whenever the cytomorphologic features are indicative of malignancy. Approximately $3 \%$ to $7 \%$ of thyroid FNAs have conclusive features of malignancy, and most are papillary carcinomas. Malignant lesions are usually treated by thyroidectomy. In this study 7 cases under this category.

In present study FNAC was done on total 411 cases, preoperative FNAC results were compared with final histopathological diagnosis in 97 patients, out of 97 cases, 85 cases showed concordance with FNAC diagnosis, 12 cases not correlated with FNAC diagnosis.

The sensitivity of thyroid FNAC ranges from $65 \%$ to $99 \%$ and its specificity from $72 \%$ to $100 \% .16-18$ In our study, the sensitivity for cytological diagnosis of neoplasia was $85.71 \%$, specificity of $100 \%$, and diagnostic accuracy was $88.65 \%$. This shows that FNAC is more specific than sensitive in detecting thyroid malignancy. Similar observations were also made by, Sumit Giri et $\mathrm{al}^{19}$, Bagga PK et al ${ }^{20}$, Prakash $\mathrm{H}$ et $\mathrm{al}^{21}$, Mahesh Kumar et $\mathrm{a}^{22}$ and Naresh pahuja et al. ${ }^{23}$

There was one false negative case in our study which was diagnosed as adenomatous goitre in FNAC. On histopathological examination it was diagnosed as follicular carcinoma. The false negative FNAC results may occur because of sampling error or misinterpretation of cytology, and are of great concern because they indicate the potential to miss malignant lesion. ${ }^{24}$

\section{CONCLUSION}

Management of patients with thyroid swellings has been radically changed by the routine use of FNAC. It has reduced the number of patients subjected to thyroidectomy for benign diseases of the thyroid. This relatively simple procedure has assumed a key role in determining of patients with thyroid swellings. However, equivocal FNAC results and diagnostic errors could not be avoided due to overlapping cytological features particularly in hyperplastic adenomatoid nodules, follicular neoplasms and follicular variants of papillary carcinomas.
TBSRTC (The Bethesda System for Reporting of Thyroid Cytology) is a vital guide for accurate management of thyroid lesions. Classifying the lesions in six categories and following the guidelines given by The Bethesda USA meetings solves all problems regarding the management of thyroid lesions and leaves no confusion. It plays a big role in establishing the uniform communications between the managing medical personnel. Marked cellularity of the smear is the problem inherent in thyroid FNAC. Increased cellularity of the smear and loss of cohesion may be present in hyperplastic/adenomatous goitre and follicular neoplasm which causes difficulty in differentiating them. This can be solved by using The Bethesda System of Reporting thyroid lesions.

\section{REFERENCES}

1. Richa Sharma, D. R. Mathur. Diagnostic Accuracy of Fine Needle Aspiration Cytology thyroid Gland Lesions. International Journal of Health Science and Research, 2012; 2: 8; pg. 1-8

2. NR, BV, TG. Comparative Study of FNAC And Histopathology In The Diagnosis Of Thyroid Swelling The Internet Journal of Head and Neck Surgery Volume 5, pg.1-5; Number 2

3. Dr. Muhammad Tariq, Dr. Muhammad Zafar Iqbal. FNAC of Thyroid Nodule; Diagnostic Accuracy of Fine Needle Aspiration Cytology. Professional Med J Dec 2010; 17(4): 589-597.

4. Martin HE, Ellis EB. Biopsy by needle puncture and aspiration. Ann Surg 1930;92(2):169-81.

5. Diagnostic Cytology: Its Origin and Principles. In Koss LG Melamed MR, editiors. Koss' Diagnostic Cytology and its Histopathologic Bases. 5th ed. Philadelphia: Lippincott Williams \& Wilkins; 2006.p.320.

6. Saleha Masood, Mahadev S Harani. Fine Needle Aspiration Cytology for Diagnosis of Thyroid Nodules and its Correlation with Histological Diagnosis Journal of Rawalpindi Medical College (JRMC); 2014; 18(2): 243-246.

7. Bugis SP, Young JKE, Archibald SD, Chen VS. Diagnostic accuracy of fine needle aspiration cytology verses frozen section in solitary thyroid nodules. Am J Surg 1986;152(4):411-6.

8. Boyd LA, Earnardt RC, Dunn JT, Frierson HF, Hanks JB. Preoperative evaluation and predictive value of fine needle aspiration and frozen section of thyroid nodules. J Am Coll Surg 1998;187(5):494-502.

9. Baloch ZW, Sack MJ, yu GH, Livolsi VA, gupta PK. Fine needle aspiration of thyroid an institutional experience. Thyroid 1998; 8: 56569.

10. Svante R Orell, Gregory F Sterrett. Fine Needle Aspiration Cytology 2012; 5th edition: page 119.

11. Lee G, Luna, HT. (ASCP). Manual of Histological Staining methods of the Armed forces Institute of Pathology; 3rd edition.pg. 34

12. Sekhar A et al.Fine Needle Aspiration Cytology Study of Thyroid Lesions - A 2 year prospective study in a Tertiary centre.International Journal of Pharmaceutical and Biological Science Archive Volume 3 Issue 1; 2015, Page No.15-19

13. HANDA $U$ et al. Role of fine needle aspiration cytology in diagnosis and management of thyroid lesions; Journal of Cytology I January 2008 / Volume 25 / Issue 1/pg. 13-17.

14. Baloch ZW, Livolsi, Asa SL, Rosai J, Merino MJ, Randolph G, et al. Diagnostic terminology and morphologic Criteria for cytologic diagnosis of thyroid lesions: a synopsis of the National Cancer Institute Thyroid Fine needle Aspiration State of the Science Conference. Diagn Cytopathol 2008;36(6):425-37 
15. Dr. Vasudha M Bhagat et al. Diagnostic Role of the Bethesda System for Reporting Thyroid Lesions: Effective Tool for Managing Thyroid Lesions: Global Journal of Medical research: Microbiology and Pathology Volume 14 Issue 1 Version 1.0 Year 2014.

16. Caraway NP, Sneige N, Samaan N. Diagnostic pitfalls in thyroid fine needle aspiration: a review of 394 cases. Diagn Cytopatho 1993; 9: 345-50.

17.Cruso D, Muzzaferri EL. Fine needle aspiration biopsy in the management of thyroid nodules. Endocrinologist 1991; 1: 1194-202.

18. Muzzaferri EL. Management of a Solitary thyroid nodule. N Eng J Med 1993: 328: 553- 9.

19. Giri $S$ et al. Fine Needle Aspiration Cytology: A Reliable diagnostic tool in Thyroid swellings; Int J Biol Med Res. 2012; 3(4): 2358-2361.

20. Bagga PK, Mahajan NC.,' Fine needle aspiration cytology of thyroid swellings: How useful and accurate is it? Indian Journal of cancer, Oct- December 2010, 47(4):437-441.

21. Prakash H Muddegowda, Jyoti B Lingegowda. International Journal of Medical and Health Science, 2012; Vol-1; Issue-1,pg- 1926

22. Kumar $M$ et al. Diagnostic Accuracy of Frozen Section in Comparison With Fine Needle Aspiration Cytology in Thyroid Lesions
- A Prospective Study; Iranian Journal of Pathology (2013) 8 (4), 219226.

23. Pahuja $\mathrm{N}$ et al. 'Significance of Cell Pattern Approach in Fine Needle Aspiration Cytology of Thyroid Lesions. International Journal of Advanced Research (2014), Volume 2, Issue 10, 1092-1101

24. Hall TL, Layfield LJ, Philippe A, Rosenthal DL. Source of diagnostic error in the fine needle aspiration of the thyroid. Cancer 1989; 63:718-25

Source of Support: Nil. Conflict of Interest: None Declared. Copyright: (c) the author(s) and publisher. IJMRP is an official publication of Ibn Sina Academy of Medieval Medicine \& Sciences, registered in 2001 under Indian Trusts Act, 1882.

This is an open access article distributed under the terms of the Creative Commons Attribution Non-commercial License, which permits unrestricted non-commercial use, distribution, and reproduction in any medium, provided the original work is properly cited.

Cite this article as: Neena Kasliwal, Sonia Tanwar, Geeta Pachori, Neha Gupta, Niti Maheshwari, Deepali Jain. Usefulness of Preoperative FNAC of Thyroid Swelling Along with Application of Bethesda System of Reporting. Int J Med Res Prof. 2016;2(3):204-09. 